\title{
Factors associated with the presence of dental plaque in an Urban cohort of elderly (Epidoso)
}

\section{Introduction}

Until the $60 \mathrm{~s}$, the elderly rarely received preventive care on caries and periodontal diseases. Thus, older individuals do not have dental preventive culture, constituting a group that does not attend the dental office frequently and when they do, the reason is usually pain or a damaged prosthesis. (NIDH_1990) ${ }^{1}$ Oral health is related to the socioeconomic and cultural conditions of the population. According to Pertesen (2005), oral health is directly related to conditions of food, housing, employment, income, environment, transport, leisure, freedom, access to health services and information. In this sense, the struggle for oral health is fundamentally linked to the improvement of social, political and economic determinants. ${ }^{2}$

However, the number of individuals fully edentulous has decreased significantly over the years. Data from the US Department of Health show that $46 \%$ of individuals between 67 and 74 were edentulous in the 70 's. This rate fell to $29 \%$ in the 90 's. Although these data do not reflect the Brazilian reality, it is clear that the preventive care implemented in recent decades allowed more people to preserve their teeth. ${ }^{3}$

Although the aging process, by itself, causes few triggering effects for impairment and disability in the oral cavity, a significant number of studies show that elderly generally have a poor oral health status. ${ }^{4-7}$

The total loss of teeth, edentulism, is still accepted by society as normal and natural with advancing age, and not as a result of the lack of preventive health policies for adults to preserve their teeth in their later years. ${ }^{8}$

Estimates based on epidemiological data indicate that edentulism decreased $10 \%$ each decade lived in the last 30 years, increasing the risk of gingival problems. ${ }^{9}$ Given that more prevalent periodontal diseases demand dental scaling and polishing, followed by intensification of oral health care by the elderly. ${ }^{10}$

Results of a survey, published in 2004 by SABE Project (Health, Wellness and aging of the Pan American Health Organization) revealed a situation similar to the study of the 80's. The Brazilian CPOD index (the sum of decayed, missing and filled teeth due to caries in an individual) aged from 65 to 74 years old reached 27.79 and the great majority derived from edentulism (92\%). In addition, only $10 \%$ of the elderly have retained at least twenty teeth. ${ }^{11}$

In 2000, the Convention of the Federation Dentaire International with focus on oral health called for the reduction of tooth loss by $25 \%$ in individuals aged 65 years old and over. This goal was not achieved in Brazil, neither was the goal of having $50 \%$ of individuals within this age range with at least 20 retained teeth. ${ }^{12}$

At reaching the goal of retaining at least 20 teeth in the oral cavity, the concerns about dental plaque will be raised, since it is the extrinsic etiologic factor of caries and periodontal disease - and the second biggest cause of dental pathology in the world's population. ${ }^{13}$

Dental plaque is a result of microorganisms that remain on surface of teeth and, mainly, in the gingival sulcus where the salivary flow,
Volume I Issue 3 - 2017

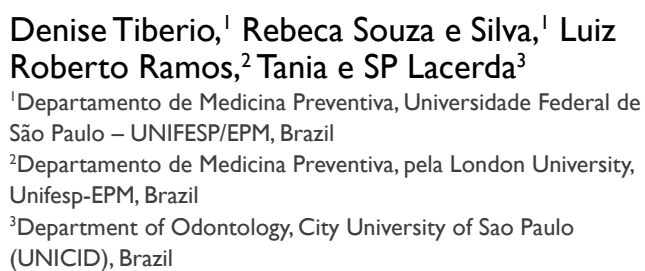

Correspondence: Tania e SP Lacerda, Department of Odontology, City University of Sao Paulo (UNICID), Brazil, Email tanialacerda@col.odo.br

Received: October 28, 2016 | Published: April II, 2017

tongue and food and lip abrasion do not provide effective natural hygiene. ${ }^{14}$

Although in the last years there have been new effective chemical substances that can reduce or eliminate plaque, like toothpaste with medication and mouthwash, dental plaque removal that leads to prevention and treatment of oral diseases should be done mechanically, mainly by brushing and flossing. ${ }^{14}$ For efficient results in tooth brushing, it has to be done daily and it requires one's time, motivation, ability and awareness. This is why some patients, especially elderly, have poor oral hygiene. ${ }^{15-17}$

The aim of this study was to detect the factors associated with dental plaque accumulation, measured by the Plaque Index- PI (O'Leary method) ${ }^{18}$ modified by Duarte (Duarte, 1994) ${ }^{19}$ in a group of elderly from Epidoso Project.

\section{Material and methods}

This work derives from a study of cohort where 600 elderly people were examined during the years 2008-2010, with the goal of evaluating the effects of motivation and efficiency of tooth brushing. The data discussed refer to the baseline information.

A subsample of men and women was created under the criteria: presence of at least 5 teeth that were not indicated for extraction, literate and with no cognitive impairment, good eyesight and hearing, preserved motor skills (data from the Comprehensive Geriatric Assessment - CGA) to assess the distribution of PI.

A single dentist performed all the PI related examinations. Sterilized flat dental mirrors were used and the standards of biosecurity were followed. Previous to gathering, pre-test calibration exercises were conducted in the pilot study with 30 elderly people that were not included in the sample. Duplicate exams were carried on in ten percent of the sample using the Kappa statistic for the calculation of reproducibility, taking the tooth as the unit of analysis for gauging the reliability of diagnosis, following the method previously described by Perez et al in $2001 .^{20}$ 
The elderly arrived at Unifesp's Center for Aging Studies (Centro de Estudos do Envelhecimento - CEE), answered to CGA (Comprehensive Geriatric Assessment) and after evaluation by trained geriatricians were referred to the various sectors, including geriatric dentistry.

After signing a Statement of Informed Consent (IC), the Plaque Index was registered (PI).This controlled clinical trial was approved by the Ethics Committee of Universidade Federal de São Paulo, under protocol number $0678 / 08$.
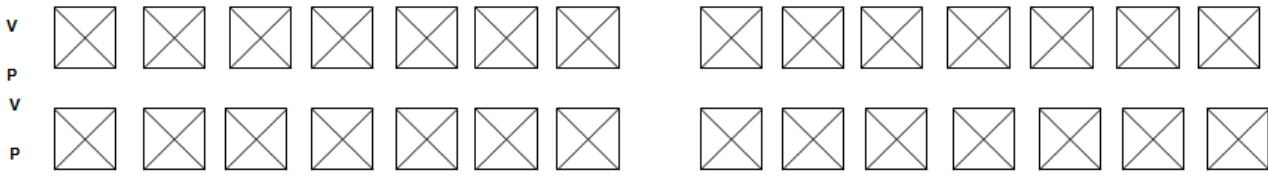

\section{Plaque index}

O'Leary Plaque Index (PI) ${ }^{18}$ was evaluated by mouth rinsing with $10 \mathrm{ml}$ of EVIFORM for 30 seconds, which revealed the tooth surfaces which had dental plaque. The counting of the stained surfaces were multiplied by 100 and divided by the number of teeth divided by 4 (surfaces of the tooth), thus revealing the percentage of surfaces compromised by plaque, being $10 \%$ considered satisfactory by the author.

765432112334567

$\underline{\text { Surfaces with dental plaque X } 100=\text { Total }}$

Total amount of teeth X 4

Pigozzo ${ }^{21}$ evaluated the main indexes to measure buccal health, getting to the conclusion that O'Leary Index (1972) is the most accurate, since it does not depend on the clinical judgment of the examiner and it is not influenced by subjective factors. It determines the presence or absence of plaque taking into account the faces of the teeth along the gum margins. ${ }^{18}$

It is an efficient test with fast acquisition, preferred by researchers when using a non populational sample. It has $10 \%$ as a satisfactory value; however, this value is very low and almost impossible to be achieved. Therefore, Duarte ${ }^{19}$ in 1994 referred 48 patients to an oral hygiene motivation program, trying to determine the average dental plaque index at the end of the experiment. O'Leary et al plaque index, Löe\&Silness gingival index and Greene-Vermilion oral hygiene index were used for this experiment. The goal was to make a comparative analysis of the three indexes, aiming to determine the highest acceptable O'Leary index to acknowledge good oral hygiene. The O'Leary index presented a statistically positive regression with index teeth, making it possible to conclude that the highest acceptable index was $27.18 \% .^{19}$

This method was chosen due to its precision, efficiency and its speed. Also because it is recommended for non-populational studies considering $27.18 \%$ of PI as acceptable.

Table I Distribution of the sample according to the PI by age, gender, income, education level, living with a partner

\begin{tabular}{llllll}
\hline Variables & & $\begin{array}{l}\text { Elderly people with PI } \\
<\mathbf{2 7 . 1 8}\end{array}$ & $\begin{array}{l}\text { Elderly people with PI } \\
\mathbf{2 7 . 1 8}\end{array}$ & $\begin{array}{l}\text { Total of elderly } \\
\text { people }\end{array}$ & $\begin{array}{l}\chi^{2} \\
\text { Pearson n }\end{array}$ \\
\hline Age & & $13(21.67)$ & $47(78.33)$ & $60(100)$ & 0.48 \\
& 60 to $69(\%)$ & $10(16.67)$ & $50(83.33)$ & $60(100)$ \\
Gender & Over 70 years old (\%) & $23(19.16)$ & $97(80.84)$ & $120(100)$ & $60(100)$ \\
& Total (\%) & $15(25)$ & $45(75)$ & $50(100)$ & 0.104 \\
\hline
\end{tabular}

\section{Statistical analyses}

For univariate analyzes we used the chi-square test to verify the existence of an association between PI - high or not - and other qualitative variables. On the other hand, in case of continuous variables, the F test was used - equivalent to Student's T test, in this case - to check the equality of mean between the two groups of PI.

Logistic regression was used for the multiple analyses. In the complete or initial model all independent variables were addressed. In the next steps non-significant variables were taken out one by one so that only the variables that altogether could represent statistical significance would remain in the final/reduced model. Second-order interactions were tested, but they were not significant. A significance level of $0.05(\mathrm{p}<0.05)$ was used in all analyses.

\section{Results}

All elderly presented high PI without significant variations, but presented some differences. It was possible to observe that older women presented lower PI when compared to men who were 70 or older ( $75 \%$ and $87.67 \%$ respectively), despite values being beyond the expected as satisfactory (Table 1). 
Table Continued...

\begin{tabular}{|c|c|c|c|c|c|}
\hline Variables & & $\begin{array}{l}\text { Elderly people with } \mathrm{PI} \\
<27.18\end{array}$ & $\begin{array}{l}\text { Elderly people with } \mathrm{PI} \\
>27.18\end{array}$ & $\begin{array}{l}\text { Total of elderly } \\
\text { people }\end{array}$ & $\begin{array}{l}\chi^{2} \\
\text { Pearson } n\end{array}$ \\
\hline & Total (\%) & $23(19.17)$ & $97(80.83)$ & $120(100)$ & \\
\hline \multirow[t]{2}{*}{ Income } & $\geq 1.5$ minimum wage $(\%)$ & $21(20.58)$ & $8 \mathrm{I}(79.42)$ & $102(100)$ & 0.34 \\
\hline & $<\mathrm{R} \$ 800.00(\%)$ & $2(11.11)$ & $16(88.89)$ & $18(100)$ & \\
\hline \multirow[t]{3}{*}{ High school } & Yes (\%) & $4(16.67)$ & $20(83.34)$ & $24(100)$ & 0.726 \\
\hline & No (\%) & $19(19.79)$ & $77(80.20)$ & $96(100)$ & \\
\hline & Total (\%) & $23(19.17)$ & $97(80.83)$ & $120(100)$ & \\
\hline \multirow[t]{2}{*}{ Living with a partner } & Yes (\%) & $9(19.14)$ & $38(80.86)$ & $47(100)$ & 0.997 \\
\hline & Total (\%) & $23(19.17)$ & $97(80.84)$ & $120(100)$ & \\
\hline
\end{tabular}

Regarding education level and the fact of living with a partner or not, the differences are very small when evaluating satisfactory PI or not (Table 1).

It was perceived that when income is evaluated a smaller PI percentage $(11.11 \%)$ is found in the elderly who have satisfactory index and belong to a group that earns less than $\mathrm{R} \$ 800.00$.

The number of teeth in the oral cavity did not show statistical difference, regarding PI with cutoff of $27.18 \%$, as it can be observed in Table 2. However, there is significant difference when the daily frequency of tooth brushing is evaluated in the group of elderly.

Table 3 shows the complete model for logistic regression of variables associated to PI. The final model is presented in Table 4 and it is possible to observe that each tooth brushing doubles the chance of having a satisfactory PI, below $27.18 \%$.

Table 2 Distribution of the sample according to PI relating to the presence of teeth and daily frequency of tooth brushing, with mean and standard deviation

\begin{tabular}{|c|c|c|c|c|c|}
\hline \multirow[t]{2}{*}{ Variables } & & \multirow{2}{*}{$\begin{array}{l}\text { Elderly people with } \\
\text { PI }<27.18\end{array}$} & \multirow{2}{*}{$\begin{array}{l}\text { Elderly people with } \\
\text { PI > } 27.18\end{array}$} & \multirow[t]{2}{*}{ Total of elderly people } & \multirow{2}{*}{$\begin{array}{l}x^{2} \\
\text { Pearsor }\end{array}$} \\
\hline & & & & & \\
\hline \multirow[t]{2}{*}{ Teeth present } & Mean & 15.06 & 15.96 & 14.85 & 0.461 \\
\hline & (DP) & $( \pm 6.46)$ & $( \pm 6.99)$ & $( \pm 6.35)$ & \\
\hline Daily frequency of tooth brushing & Mean (DP) & $2.72(0.80)$ & $3.13(0.75)$ & $2.62(0.79)$ & $0.007 *$ \\
\hline
\end{tabular}

Table 3 Complete model for logistic regression of variables associated to PI

\begin{tabular}{llll}
\hline Variables & 6 & Or & Significance \\
\hline Age & -0.06 & 0.942 & $0.17 \mathrm{I}$ \\
Gender & -0.784 & 0.457 & 0.206 \\
Living with a partner & $0.52 \mathrm{I}$ & $\mathrm{I} .684$ & 0.395 \\
Frequency of daily tooth brushing & 0.692 & $\mathrm{I} .998$ & $0.039 *$ \\
Education level & $-0,216$ & 0,806 & $0,75 \mathrm{I}$ \\
Income & 0.752 & 2.121 & 0.348 \\
Teeth present & 0.1 & $\mathrm{I} .0 \mathrm{I}$ & 0.432 \\
\hline
\end{tabular}

Table 4 Reduced Model of logistic regression for PI*

\begin{tabular}{llll}
\hline Variables & B & Or & Significance \\
\hline Constant & $-3.46 \mathrm{I}$ & $0.03 \mathrm{I}$ & 0 \\
$\begin{array}{l}\text { Number of times tooth brushing } \\
\text { was carried on }\end{array}$ & 0.709 & 2.032 & 0.18 \\
\hline
\end{tabular}

\section{Discussion}

Epidemiological surveys carried out in Brazil and abroad have demonstrated the serious oral health problems that affect people in different countries. The socio-economic and cultural factors of our population have been the cause of numerous problems related to oral health. Dental caries and periodontal disease are closely related to these conditions, presenting high prevalence, therefore being a serious health problem.

Until the 90s Dentistry in Brazil was limited to eliminating pain, that is, its aim was to cure only. Over the years, this kind of thinking gave way to a philosophy of work which did not aim only at pain elimination but also at its cause. It is then Preventive Dentistry for which the principle is based on the prevention of oral diseases through control of its etiology, which in case of dental caries and periodontal disease, it is known as biofilm or plaque. This control can be done by mechanical or chemical agents or through a combination of both.

The mechanical means, which include tooth brushing and flossing can be performed both by the professional or by the patient according to Fischman, ${ }^{22}$ and they should be the chosen method as they are the safest and the most efficient ones. The myth that aging leads to loss of all teeth added to the lack of initiatives aimed at controlling plaque 
in the elderly can influence the elderly to neglect plaque control measures.

The PI value found in this study is very worrying as only around $20 \%$ of the evaluated individuals presented PI with satisfactory indexes; these values were lower than the ones found in literature ${ }^{23,24}$ However, it should be emphasized that such studies came to these values through different methodologies from the one of the present study. The current study found an average of 15 teeth present, similar to the 2009 study, ${ }^{17}$ but with slight higher values than in literature. ${ }^{25,26}$

Regarding dental plaque, $80.82 \%$ of elderly presented Plaque Indexes higher than the maximum considered satisfactory (its value is $27.18 \%$ ), which can harm the respiratory system. ${ }^{27}$ In a study with young people, there was an association of unsatisfactory PI to ow socio-economic situation ${ }^{28}$ which was not concluded in our study, maybe for having a sample constituted of elderly.

Queiroz ${ }^{29}$ states that although age is not synonymous with disease, old age increases the risk of the functional capacity impairment, with the consequent loss of autonomy and independence. Perhaps this information justifies why this index is more prevalent in elderly aged older than 70 .

Mini-Mental State Examination (MMSE) ${ }^{30}$ is a test in which results below 25 lead to suspect cognitive impairment. Studies show association of functional disability with cognitive deficit, ${ }^{31}$ creating the expectation of finding unsatisfactory PI values for the elderly with MMSE below 25. This result was not found as elderly with MMSE below 25 were not included in the sample.

The results of the study point to the fact that brushing more than twice a day is a protective factor for the deposit of plaque, similar to the studies in $2002^{32}$ in which 62 dentistry students brushed their teeth in the usual way for three consecutive times, the results indicated that the plaque reduction was significant after each of the three brushings, suggesting that with only two the level of dental plaque has reached the expected results for effective brushing. One has to reflect that this study evaluated young people and consecutive brushings, in contrast to our study, but it seems that older people do not have the same frequency of brushing as the young.

The comparison to other works related to satisfactory values of PI should be cautious, since the PI in the literature is assessed in different ways and with different satisfactory values. More studies evaluating the plaque index in the elderly are required.

\section{Conclusion}

High prevalence of unsatisfactory PI in the studied sample points to the need of developing interventions that aim at motivating oral hygiene among the elderly. Considering that as the number of daily tooth brushing decreases in $18 \%$ at each increment unit - varying from 1 to 5 , a first step could be stimulating more frequency in daily tooth brushing.

\section{Acknowledgements}

None.

\section{Conflict of interest}

Author declares there is no conflict of interest in publishing the article.

\section{References}

1. National Institute for Dental Research. Epidemiology and Oral Disease Prevention Program. Oral health of US adults, Washington, USA; 1985-1986.

2. Petersen PE, Bourgeoi D, Ogawa H, et al. The global burden of oral diseases and risks to oral health. Bull World Health Organ. 2005;83(9):661-669.

3. US Department of Health and Human Services. Oral Health in America: a report of surgeon general. Department of Health and Human Services, National Institute of Health, USA; 2000.

4. Silva SRC, Valsecki JA. Evaluation of elderly oral health conditions in a Brazilian municipality Rev Panam Salud Publica. 2000;8(4):268-7.

5. Colussi CF, Freitas SF. Epidemiological aspects to the elderly oral health in Brazil. Cad Saúde Publica. 2002;18(5):1313-1320.

6. Colussi CF, Freitas SFT, Calvo MCM. Epidemiological profile of caries and the use of prosthesis in the elderly population from Biguaçu. Revista Brasileira de Epidemiologia. 2004;7(1):88-97.

7. Reis SCGB, Higino MASP, Melo HMD, et al. Oral health conditions of institutionalized elderly in Goiânia, GO. Revista Brasileira de Epidemiologia. 2005;8(1):67-73.

8. Ellis JS1, Levine A, Bedos C, et al. Refusal of implant supported mandibular overdentures by elderly patients. Gerodontolgy. $2011 ; 28(1): 62-68$

9. Douglass CW, Shih A, Ostry L. Will there be a need for complete dentures in the United States in 2020? J Prosthet Dent. 2002;87(1):5-8.

10. Tibério D, Santos MTBR, Ramos LR. Periodontal status and the need of treatment in elderly. Rev Assoc Paul Cir Den. 2005;59(1):69-72.

11. Brazilian Ministry of Health. SB Brasil Project: oral health status of the Brazilian population Office of Attention to Health. Basic Attention Department, Oral Health Coordination, Brazil; 2004.

12. Petersen PE. Global policy for improvement of oral health in the $21 \mathrm{st}$ century - implications to oral health research of World Health Assembly 2007, World Health Organization. Community Dentistry and Oral Epidemiology. 2009;37(1):1-8,

13. Petersen PE, Ogawa H. Strengthening the prevention of periodontal disease: the WHO approach. J Periodontol. 2005;76(12):2187-93.

14. Lindhe J. Clinical Periodontology Treaty. Rio de Janeiro, 2nd edn. Guanabara Koogan, Brazil; 1992.

15. Mastrantonio SDS, Garcia PPNS. Educational program on oral health - Literature review - J Brás Odontopediatria \& Odontol Bebê 2002;(25):215-22

16. Tanaka F, Gomes LC, Pereira SK. Preventive methods used to control dental caries Revista Ibero - americana de odontologia estética \&Dentística. 2004;3(11):209-310.

17. Tiberio D, Campanha AL, Ramos LR. Dental biofilm: a challenge in geriatric dentistry. Perionews. 2009;3(4):299-304.

18. O'Leary TJ, Drake RB, Naylor JE. The plaque control Record. J. Periodontol. 1972;43(1):38-42.

19. Duarte CA. Critical evaluation of the O'Leary index in relation to Greene-Vermillion and Lôe\&Silness indexes. Rev Odontol Univ São Paulo. 1994;8(4):301-307.

20. Peres, Traebert JL, Marcenes W. Standardizing examiners for epidemiological studies of dental caries. Caderno de saúde Publica. 2001; 17:153-159. 
21. Pigozzo MM, Laganá DC, Campos TN, et al. The importance of the indexes in deontological clinic research: a literature review. Revista de Odontologia da Universidade Cidade de São Paulo. 2008;20(3):280-7.

22. SL Fischman. The history of oral hygiene products: how far have we come in 6000 years? Periodontology 2000. 1997;15(1):7-14.

23. Peres SHC, Peres AS. The determinants of socioeconomical conditions in the third age oral health. RPG Rev Pós-grad. 2003;10(4):369-75.

24. Silva FP, Cardoso JR, Miranda QE, et al. Geriatric patients profile from Paulo Tarso Hospital. Arq Odontol Belo Horizonte. 2005;41(1):65-74.

25. Mesas AE, Andrade SM, Cabrera MAS. Oral health conditions of the elderly from an urban community in Londrina, Paraná. Rev Bras Epidemiol. 2004;9(4):471-80.

26. Lilian Berta Rihs, Débora Dias da Silva, Maria da Luz Rosário de Sousa. Dental caries in an elderly population in Brazil. J Appl Oral Sci. 2009; 17(1):8-12.
27. Abe $\mathrm{S}$, Ishihara $\mathrm{K}$, Adachi $\mathrm{M}$, et al. Oral hygiene evaluation for effective oral care in preventing pneumonia in dentate elderly. Archives of Gerontology and Geriatrics. 2006;43(1):53-64.

28. Abegg C. Buccal hygiene of adults from Porto Alegre. Rev Saúde Pública. 1997;31(6):586-593.

29. Queiroz ZPV. Elderly care: a social approach. O mundo da saúde. 2000;24(24):246-48.

30. Folstein MF, Folstein SE, McHugh PR. "Mini-mental state". A practical method for grading the cognitive state of patients for the clinician". $J$ Psychiatr Res. 1975;12(3):189-98.

31. Schneider RH, Marcolin D, Dalacorte RR. Functional evaluation of elderly. Scientia Medica, Porto Alegre; 2008;18(1):4-9.

32. Vargas, AM D, Abreu MV, et al. Evaluation of buccal hygiene method. Rev do CROMG. 2002;8(2):144-147. 